\title{
Preparation of Macroporous Semiconductive Materials for the Sensing of Sulfur Compounds
}

\author{
No-Kuk Park, Tae Hoon Lee, Min Jung Kim and Tae Jin Lee* \\ School of Chemical Engineering and Technology, \\ 214-1 Daedong Gyeongsan, Gyeongbuk 712-749, Korea
}

(Received July 14, 2014; accepted December 16, 2014)

Key words: macroporous, tin oxide, gas sensor, hydrogen sulfide

In this study, macroporous $\mathrm{SnO}_{2}$ was prepared for the sensing of sulfur compounds, which are used as odorants to improve the safety of natural gas. Macropores in the semiconducting $\mathrm{SnO}_{2}$ were formed using polystyrene nanobeads as a template. The mixing ratio of the polystyrene colloid and tin chloride solution used as the precursors was controlled to form an ordered array of macropores. The chemical sensing properties of the macroporous $\mathrm{SnO}_{2}$ were investigated by injecting sulfur compounds into the sensing chamber using an $I-V$ source meter. The macroporous $\mathrm{SnO}_{2}$ materials were highly sensitive to sulfur compounds.

\section{Introduction}

Semiconducting tin oxide exhibits good chemical gas sensing properties towards a range of gases. ${ }^{(1)}$ One of the most common ways to tune the sensitivity and selectivity of these materials is to dope them with various noble metals. ${ }^{(2)}$ The gas sensing performance of various sensing materials can simply be enhanced by controlling their morphological features during chemical synthesis. In particular, the generation of highly specific surface areas and uniform systems of large pores increases the probability of a gas interacting with a semiconductor, which is likely to increase the sensitivity of the material. The concept of utilizing self-assembled arrays of amphiphiles to synthesize well-ordered mesoporous materials ${ }^{(3)}$ has recently been applied to tin oxide $\left(\mathrm{SnO}_{2}\right)$. $\mathrm{SnO}_{2}$ is the most widely used n-type semiconductor in gas-sensing devices because of its ability to detect combustible gases, such as $\mathrm{CH}_{4}, \mathrm{C}_{2} \mathrm{H}_{5} \mathrm{OH}, \mathrm{CO}$, and $\mathrm{H}_{2}$. The $\mathrm{SnO}_{2}$ based sensor is generally operated at $250-500{ }^{\circ} \mathrm{C}$ in air. $\mathrm{SnO}_{2}$ adsorbs oxygen from the atmosphere, forming an electron-depleted zone. Reducing gases react with the adsorbed oxygen, increasing the electron concentration in the material and decreasing the electrical resistance.

${ }^{*}$ Corresponding author: e-mail: tjlee@ynu.ac.kr 
Recently, a coal gasification process, which produces a synthetic gas (syn-gas), has been developed for electrical power generation and coal-to-liquid oil processes. However, sulfur compounds of 5000 ppmv are contained in the syn-gas produced in the coal gasification process, and cause the corrosiveness problems of the facilities and catalyst in the electrical power generation and catalytic chemical conversion processes. Therefore, sulfur compounds must be removed for a stable energy process. Thus, the detection of sulfur compounds contained in syn-gas is very important. Various $\mathrm{SnO}_{2}$ based gas sensors were developed for the detection of hydrogen sulfide. ${ }^{(6-9)}$ The metaldoped $\mathrm{SnO}_{2}$ and $\mathrm{SnO}_{2}$-transition metal oxide composite materials were synthesized in order to enhance the sensitivity of a gas sensor. The calcination temperature for the synthesis of $\mathrm{SnO}_{2}$ was controlled for high-crystallinity $\mathrm{SnO}_{2}{ }^{(10,11)}$ In this study, macroporous $\mathrm{SnO}_{2}$ was prepared and used as a gas-sensing material for the detection of small-content $\mathrm{H}_{2} \mathrm{~S}$ in the syn-gas purified in the sulfur removing process. Although the sensitivity of a $\mathrm{SnO}_{2}$-based sensor increases with increasing $\mathrm{H}_{2} \mathrm{~S}$ content, it decreases at a low $\mathrm{H}_{2} \mathrm{~S}$ content. Therefore, the increases in contact area over the sensor and gas diffusion rate were carried out with the synthesis of macroporous $\mathrm{SnO}_{2}$ in this study.

In this study, macroporous $\mathrm{SnO}_{2}$ was prepared using a polystyrene (PS) nanobead template in order to provide an effective pathway for the sensing of sulfur compounds, such as $\mathrm{H}_{2} \mathrm{~S}$. It could be expected that the macroporous $\mathrm{SnO}_{2}$ has better sensing properties than nonporous $\mathrm{SnO}_{2}$ because the macroporous $\mathrm{SnO}_{2}$ has a larger surface area and an interconnected macroporous structure enhances gas diffusion. The macroporous $\mathrm{SnO}_{2}$ was prepared by the addition of polystyrene nanobeads as a template. Polystyrene nanobeads were synthesized by the suspension polymerization method. The sensing properties of the macroporous $\mathrm{SnO}_{2}$ were compared with those of the nonporous $\mathrm{SnO}_{2}$, which was prepared by a precipitation method.

\section{Materials and Methods}

\subsection{Synthesis of polystyrene nanobeads}

A polystyrene colloid was used as a template additive for the formation of pores in the semiconducting materials and synthesized as spherical particles by the polymerization of a styrene monomer (Sigma-Aldrich, $\mathrm{C}_{6} \mathrm{H}_{5} \mathrm{CH}=\mathrm{CH}_{2}, \mathrm{MW}=104.15$ ). The polystyrene nanobeads were prepared in an experimental setup equipped with a $500 \mathrm{ml}$ jacketed glass vessel, a magnetic stirrer, a condenser, a vacuum system, a nitrogen flow system, and a thermocouple by the suspension polymerization method. The temperature was controlled using a PID controller and kept within $\pm 0.1{ }^{\circ} \mathrm{C}$. The narrowly dispersed latex was prepared by the surfactant-free emulsion polymerization of styrene. Millipore water (468 $\mathrm{ml})$ and styrene $(0.11 \mathrm{~mol})$ were charged in the reactor. The reactor was purged with alternate cycles of nitrogen and evacuation, and finally left under a nitrogen atmosphere. After heating the reaction mixture to $70{ }^{\circ} \mathrm{C}$ with constant stirring at $400 \mathrm{rpm}$, the initial solution $(0.42 \mathrm{~g}, 1.5 \mathrm{mmol}$ of KPS in $10 \mathrm{ml}$ of water) was injected into the reactor through a syringe. The reaction was allowed to proceed under these conditions for $12 \mathrm{~h}$. 


\subsection{Synthesis of macroporous $\mathrm{SnO}_{2}$}

The synthesis of macroporous $\mathrm{SnO}_{2}$ was carried out in a rotary vacuum evaporator. A mixture solution $(100 \mathrm{ml})$, consisting of a $0.05 \mathrm{M} \mathrm{SnCl}_{4}$ solution and a polystyrene colloid $(50 \mathrm{ml})$, was placed in a $500 \mathrm{ml}$ round flask. The volumetric ratio of $\mathrm{SnCl}_{4}$ and the polystyrene colloidal solution was fixed to $1 / 1$. The glass substrate was placed at the bottom of a glass container. The water in the mixture solution was removed by vacuum evaporation at $50{ }^{\circ} \mathrm{C}$. After evaporation, the resulting solid mixture, which consisted of polystyrene spherical nanobeads and $\mathrm{SnCl}_{4}$, was calcined at $600{ }^{\circ} \mathrm{C}$ for $4 \mathrm{~h}$ on an alumina substrate to thermally decompose the polystyrene used as the template. The physical properties of the macroporous $\mathrm{SnO}_{2}$, such as surface area, crystal structure and surface morphology, prepared in this study were also examined by the nitrogen adsorption method, X-ray diffraction (XRD) and scanning electric microscopy (SEM). The alumina substrate, $10 \times 10 \mathrm{~mm}^{2}$ in size and coated with a platinum thin layer, was used as the electrode material for the fixation of macroporous $\mathrm{SnO}_{2}$, as shown in Fig. 1. The macroporous $\mathrm{SnO}_{2}$ powder was prepared as a slurry phase using isopropyl alcohol as a dispersant. The macroporous $\mathrm{SnO}_{2}$ in the slurry phase was deposited over the alumina substrate.

\subsection{Measurement of sensing properties of macroporous $\mathrm{SnO}_{2}$}

The electrical properties of the macroporous $\mathrm{SnO}_{2}$ used as the chemical gas-sensing material were examined using an $I-V$ meter (SourceMeter 2635A, Keithley) and the electrical current of the macroporous $\mathrm{SnO}_{2}$ at $200{ }^{\circ} \mathrm{C}$ was measured by allowing a source voltage of $10 \mathrm{~V}$ to pass through a platinum electrode on the substrate. The alumina substrate of the gas sensor was patterned onto a platinum electrode. The electrical properties of the macroporous $\mathrm{SnO}_{2}$-based chemical sensor were analyzed by the adsorption and desorption of $\mathrm{H}_{2} \mathrm{~S}$ in the experimental setup, and the electric resistance was measured over the macroporous $\mathrm{SnO}_{2}$. The experimental setup for the sensing of $\mathrm{H}_{2} \mathrm{~S}$ consisted of a mass flow controller (MFC) to control the gas composition, an electrical oven to control the sensing temperature, a sensing chamber to allow contact between the $\mathrm{H}_{2} \mathrm{~S}$ and macroporous $\mathrm{SnO}_{2}$ coated on the sensor device, and an $I-V$ source

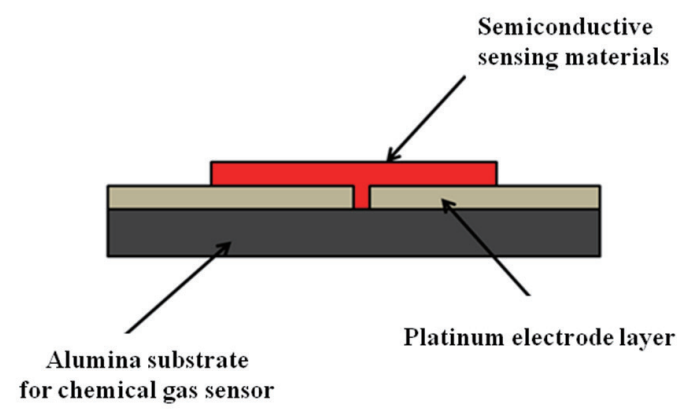

Fig. 1. (Color online) Schematic diagram of the chemical gas sensor. 
meter to measure the electric resistance, as shown in Fig. 2. The sensing temperature was fixed to $200{ }^{\circ} \mathrm{C}$ to examine the response of the macroporous $\mathrm{SnO}_{2}$ used as a chemical sensor, and the $\mathrm{H}_{2} \mathrm{~S}$ content was fixed at 50.9 ppmv. The $\mathrm{H}_{2} \mathrm{~S}$ adsorption and desorption steps were repeated for three cycles under all experimental conditions and the adsorption step was carried out at the maximum current. The measured currents were used as the data for analyzing the response with the injection of $\mathrm{H}_{2} \mathrm{~S}$.

\section{Results and Discussion}

\subsection{Analysis of the physical properties of macroporous $\mathrm{SnO}_{2}$}

Spherical polystyrene nanobeads were synthesized by the suspension polymerization method, and their size was approximately $300 \mathrm{~nm}$, as shown in Fig. 3. The size of the polystyrene nanobeads was controlled by the concentration of styrene monomer used in the polymerization process. Ordered macroporous materials were synthesized with polystyrene nanobeads owing to their homogeneous spherical size.

The macrosized pores formed over the surface of the $\mathrm{SnO}_{2}$ layer prepared in this study were examined, as shown in Fig. 4. Macropores were formed in the $\mathrm{SnO}_{2}$ bulk

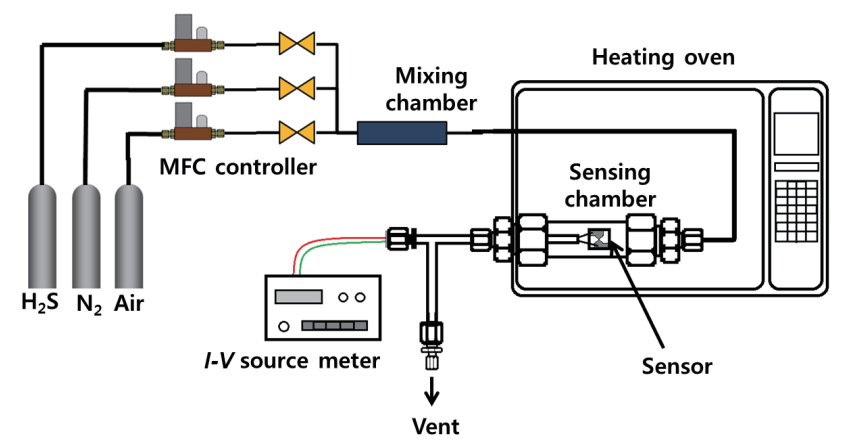

Fig. 2. (Color online) Schematic diagram of the experimental apparatus for measuring the responses of the chemical gas sensor.

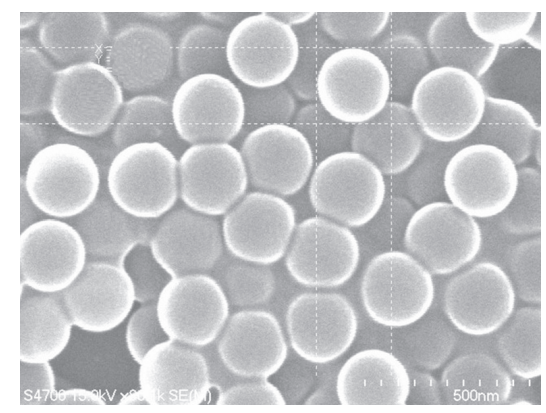

Fig. 3. SEM image of the polystyrene nanobeads synthesized by the suspension polymerization method. 


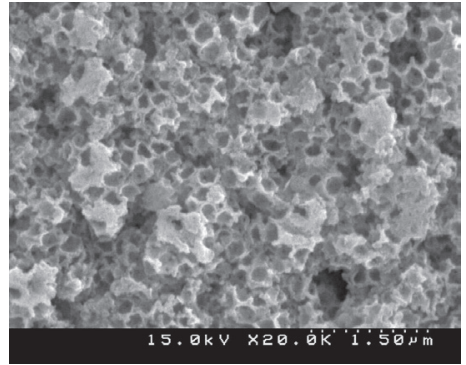

(a)

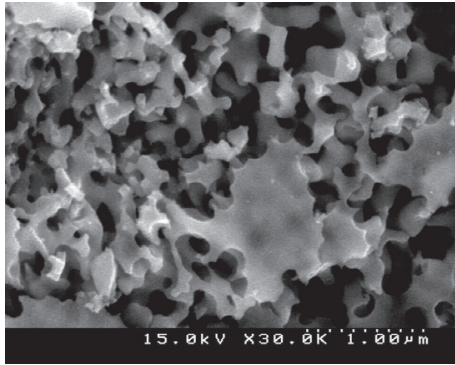

(b)

Fig. 4. SEM images of the macroporous $\mathrm{SnO}_{2}$ prepared with the polystyrene nanobeads: (a) $\times 20000$ and $($ b) $\times 30000$.

powder. The size of the pores matched that of the polystyrene nanobeads used as the template for the formation of macropores in $\mathrm{SnO}_{2}$. The ordered macropores formed in $\mathrm{SnO}_{2}$ were spherical. These spherical macropores were interconnected in the $\mathrm{SnO}_{2}$ bulk and dispersed homogeneously, as shown in Fig. 4(b). Therefore, the $\mathrm{SnO}_{2}$-based chemical gas sensor showed a strong response because the gases diffused well into the $\mathrm{SnO}_{2}$ bulk layer.

The surface areas of the macroporous $\mathrm{SnO}_{2}$ and nonporous $\mathrm{SnO}_{2}$, which were prepared by a precipitation method, were measured by the nitrogen adsorption method. The two $\mathrm{SnO}_{2}$ samples showed substantially different surface areas. The surface area of $\mathrm{SnO}_{2}$ prepared by the precipitation method was approximately $17 \mathrm{~m}^{2} / \mathrm{g}$ and that of macroporous $\mathrm{SnO}_{2}$ was approximately $54 \mathrm{~m}^{2} / \mathrm{g}$. $\mathrm{SnO}_{2}$ is a nonporous material, but it is highly sensitive to many types of gases. The isotherm curves obtained by nitrogen adsorption and desorption exhibited a typical low pore volume, as shown in Fig. 5(a). On the other hand, the pore size distribution (PSD) curve measured by nitrogen adsorption and $\mathrm{Hg}$ porosimetry confirmed that macroporous $\mathrm{SnO}_{2}$ has meso and macropore sizes of approximately 33 and $130 \mathrm{~nm}$, as shown in Figs. 5(b) and 6.

XRD showed that the macroporous $\mathrm{SnO}_{2}$ had high crystallinity with a tetragonal structure, as shown in Fig. 7(a). The XRD peak pattern of the macroporous $\mathrm{SnO}_{2}$ revealed the same structure as the common $\mathrm{SnO}_{2}$ prepared by the precipitation method, as shown in Fig. 7(b). Therefore, the effects of the surface area and gas diffusion on chemical gas sensitivity can be determined with the formation of macropores in the $\mathrm{SnO}_{2}$ bulk. The peaks of 28,41 , and $51^{\circ}$ of $2 \theta$, as shown in Fig. 7(a), agreed with the XRD pattern of $\mathrm{KCl}$, which was formulated from potassium in the initiator (KPS) and chlorine in the precursor $\left(\mathrm{SnCl}_{2}\right)$.

\subsection{Response of macroporous $\mathrm{SnO}_{2}$ for $\mathrm{H}_{2} \mathrm{~S}$}

In this study, the changing electric current of the macroporous $\mathrm{SnO}_{2}$ deposited on the chemical sensor was examined by the addition of hydrogen sulfide or air into the sensing chamber. Hydrogen sulfide and air were introduced alternately into the sensing chamber, and these experiments were performed repeatedly for 3 cycles. Air was used as the purge gas for the desorption of hydrogen sulfide adsorbed over the macroporous $\mathrm{SnO}_{2}$, and the 


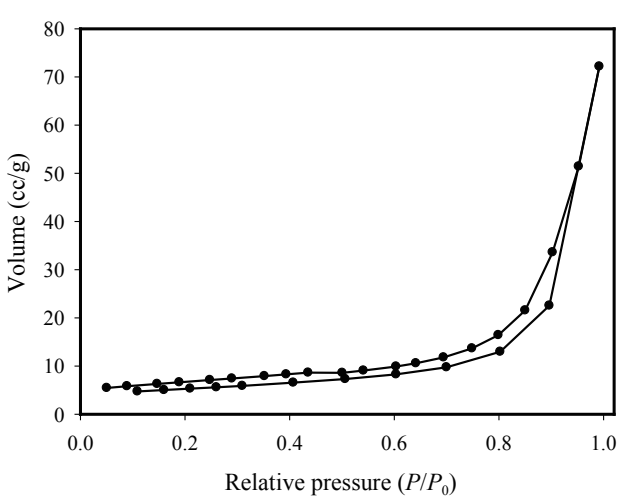

(a)

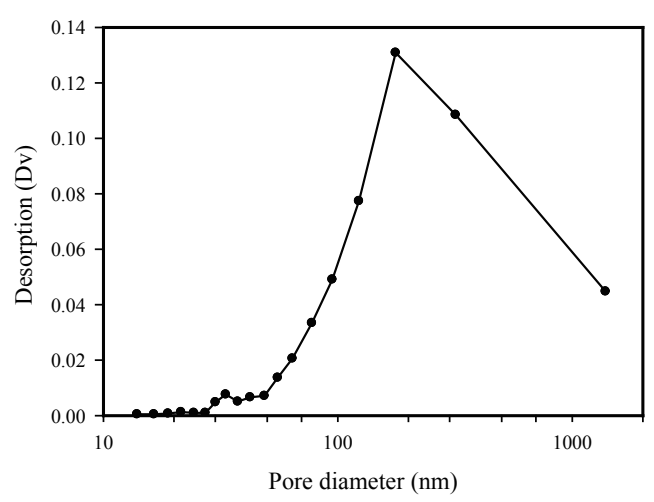

(b)

Fig. 5. (a) Isotherm and (b) pore size distribution curves of macroporous $\mathrm{SnO}_{2}$ measured by nitrogen adsorption and desorption.

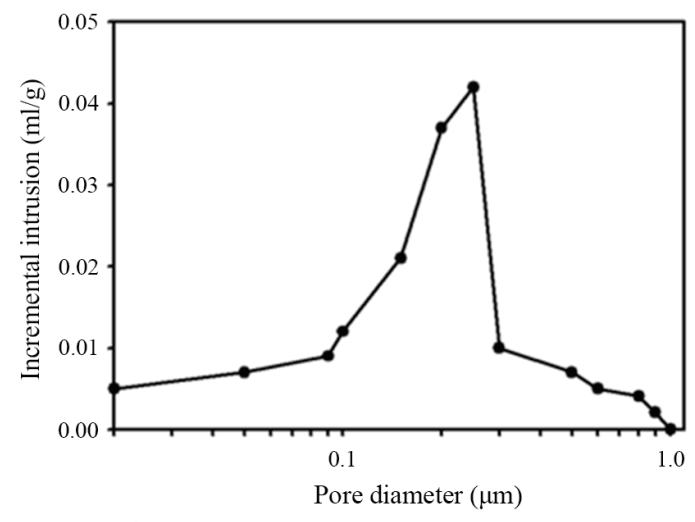

Fig. 6. Pore size distribution curve of macroporous $\mathrm{SnO}_{2}$ measured by $\mathrm{Hg}$ porosimetry.

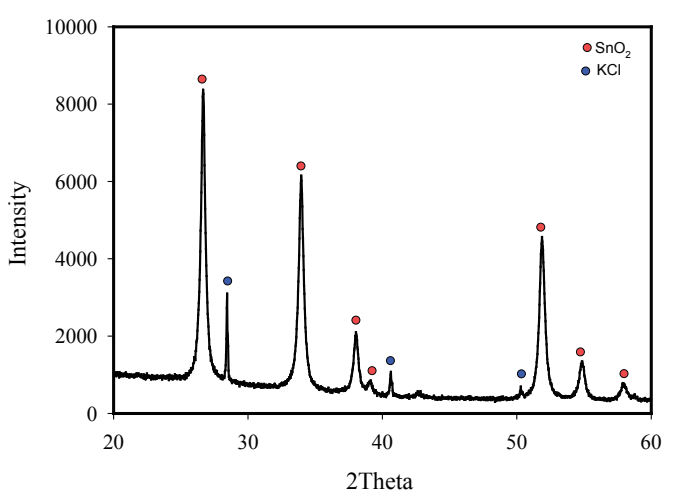

(a)

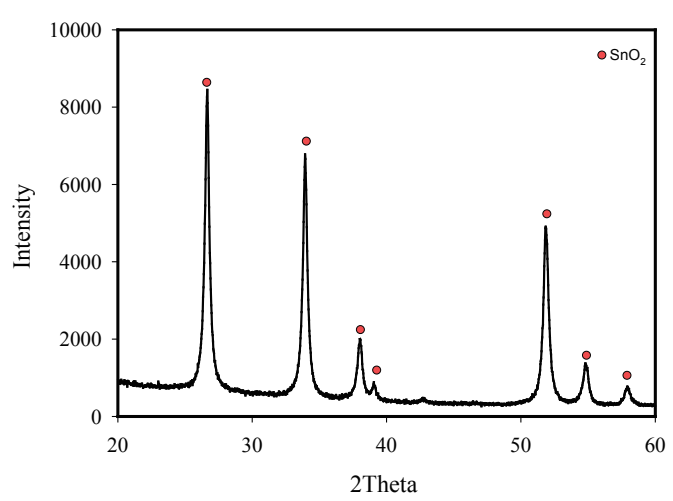

(b)

Fig. 7. (Color online) XRD patterns of (a) macroporous $\mathrm{SnO}_{2}$ and (b) nonporous $\mathrm{SnO}_{2}$. 
oxygen contained in the air was used as a regeneration gas for the reoxidation of S-doped $\mathrm{SnO}_{2}$ formulated by a gas-solid reaction between hydrogen sulfide and $\mathrm{SnO}_{2}$. Figure 8 shows the response signals obtained with 50.9 ppmv hydrogen sulfide at $200{ }^{\circ} \mathrm{C}$. When $\mathrm{H}_{2} \mathrm{~S}$ was flowed into the sensing chamber, the electric current increased from 20 to 235 $\mu \mathrm{A}$ during the first cycle, from 15 to $240 \mu \mathrm{A}$ during the second cycle, and from 10 to 253 $\mu \mathrm{A}$ during the third cycle. The consumption times reached by the maximum currents were approximately 250,350, and 490 at the first, second, and third cycles, respectively. The response time increased with increasing number of cycles and the maximum electric current increased. The current decreased rapidly when the sensing chamber was purged with air and recovered within $50 \mathrm{~s}$. Moreover, the response time for $\mathrm{H}_{2} \mathrm{~S}$ in the macroporous $\mathrm{SnO}_{2}$ was increased about 2 times with only 3 cycles. It was concluded that the response time increased, because the concentration of hydrogen sulfide was reduced by mixing air and hydrogen sulfide in the gas mixing chamber at the injection times of the second and third cycles. The gas mixing chamber was located in front of the sensing chamber for the control of $\mathrm{H}_{2} \mathrm{~S}$ concentration.

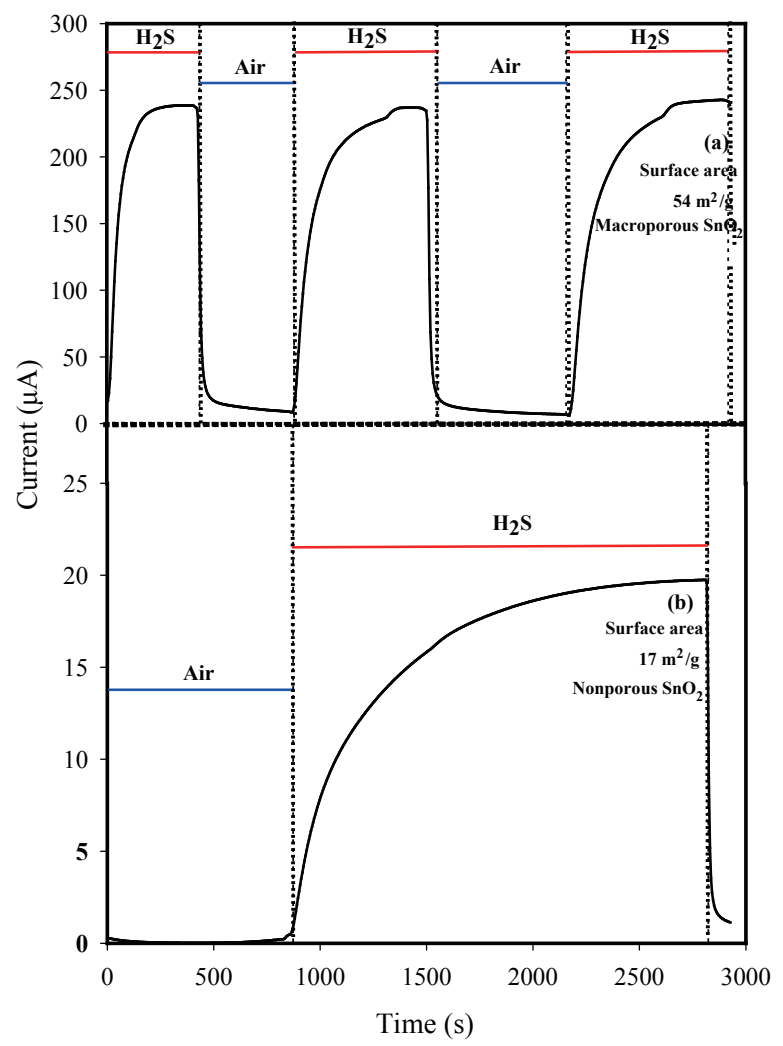

Fig. 8. (Color online) Electric currents measured over (a) macroporous $\mathrm{SnO}_{2}$ and (b) nonporous $\mathrm{SnO}_{2}$-based chemical sensors with $50.9 \mathrm{ppmv}_{2} \mathrm{~S}$ at $200{ }^{\circ} \mathrm{C}$ using an $I-V$ source meter, alternately inputting $\mathrm{H}_{2} \mathrm{~S}$ and air. 
When nonporous $\mathrm{SnO}_{2}$ was used as the sensing material, the electric current increased slowly with the injection of hydrogen sulfide and reached a maximum value of $20 \mu \mathrm{A}$ at approximately $1700 \mathrm{~s}$. The sensing response of the nonporous $\mathrm{SnO}_{2}$ was both lower and slower than that of the macroporous $\mathrm{SnO}_{2}$. Gas diffusion was enhanced by the macrosized pores in the $\mathrm{SnO}_{2}$ bulk because the difference in sensing property for hydrogen sulfide depends on the surface area and morphology of the sensitive materials.

\section{Conclusions}

In this study, macroporous $\mathrm{SnO}_{2}$ was prepared by the addition of polystyrene nanobeads used as the template. These nanobeads were synthesized by the suspension polymerization method. Macroporous $\mathrm{SnO}_{2}$ has a higher surface area than nonporous $\mathrm{SnO}_{2}$. The macropores interconnected in the $\mathrm{SnO}_{2}$ bulk enhance gas diffusion in the sensing materials. Therefore, high sensitivity can be obtained with the formation of macropores in the $\mathrm{SnO}_{2}$ bulk due to the effects of the surface area and gas diffusion.

\section{Acknowledgements}

This study was supported by a 2014 Yeungnam University Research Grant and Basic Science Research Program through the National Research Foundation of Korea (NRF) funded by the Ministry of Education (No. 2013R1A1A2059804).

\section{References}

1 J. Q. Sun, J. S. Wang, X. C. Wu, G. S. Zhang, J. Y. Wei, S. Q. Zhang, H. Li and D. R. Chen: Cryst. Growth Des. 6 (2006) 1584.

2 D. Kohl: Sens. Actuators 18 (1989) 71.

3 Y. Wang, X. Wie, Y. Li and Z. Zhou: Solid State Electron. 48 (2004) 627.

4 Y.-H. Choi, M. Yang and S.-H. Hong: Sens. Actuators B 134 (2008) 117.

5 T. K. H. Starke and G. S. V. Coles: Sens. Actuators B 88 (2003) 227.

6 S. Shukla, S. Patil, S. C. Kuiry, Z. Rahman, T. Du, L. Ludwig, C. Parish and S. Seal: Sens. Actuators B 96 (2003) 343.

7 J. Liu, X. Huang, G. Ye, W. Liu, Z. Jiao, W. Chao, Z. Zhou and Z. Yu: Sensors 3 (2003) 110.

8 T. Maekawa, J. Tamaki, N. Miura and N. Yamazoe: Chem. Lett. 20 (1991) 575.

9 X. Xue, L. Xing, Y. Chen, S. Shi, Y. Wang and T. Wang: J. Phys. Chem. C 112 (2008) 12157.

10 L. He, Y. Jia, F. Meng, M. Li and J. Liu: J. Mater. Sci. 44 (2009) 4326.

11 S. C. Lee, S. Y. Kim, B. W. Hwang, S. Y. Jung, D. Ragupathy, I. S. Son, D. D. Lee and J. C. Kim: Sensors 13 (2013) 3889. 